\title{
B creechoadhiristrdivointenpdaencortetosdepandemia
}

\author{
Recibido: 7 de mayo de 2020 • Aprobado: 2 de junio de 2020 \\ https://doi.org/10.22395/ojum.v19n40a3
}

\author{
Hernán Darío Vergara Mesa \\ Universidad de Antioquia, Medellín, Colombia \\ hernan.vergara@udea.edu.co \\ https://orcid.org/0000-0003-2288-2182
}

\section{RESMEN}

A partir de las bases fundacionales del derecho administrativo como disciplina jurídica, se examinan dos problemáticas que surgen como consecuencia de la pandemia por la COVID-19 relacionadas con el control y la eficacia de sendas medidas adoptadas por las autoridades desde el esquema metodológico de la proporcionalidad. Se pretende demostrar que la legalidad administrativa es una construcción que depende de los sectores de referencia y de los bienes jurídicos comprometidos por la actuación estatal, y que las competencias constitucionales no son estáticas o absolutas cuando se deben enfrentar a circunstancias excepcionales.

Palabras clave: principio de legalidad; principio del control; autonomía; principio de eficacia; orden público; examen de proporcionalidad. 


\section{AdninistraivelawlnterpellatesinPandenic Contexts ABSTRAC}

Based on the foundations of administrative law as a legal discipline, two problems are examined which emerge as a consequence of the COVID 19 pandemic, related with control and efficiency of each one of the measures deployed by the authorities from the methodological schema of proportionality. This study aims towards proving that administrative legality is a construction dependant on the reference sectors and the legal assets compromised by State actions and that the constitutional competencies are not static or absolute when exceptional circumstances must be confronted.

Keywords: legality principle; control principle; autonomy; efficiency principle; public order; proportionality exam.

\section{ODreitoAdministrativointerpela emcontextos de pendemia} PESMD

A partir das bases fundacionais do Direito Administrativo como disciplina jurídica, são examinadas duas problemáticas que surgem como consequência da pandemia da Covid-19, relacionadas com o controle e eficácia das medidas adotadas pelas autoridades, por meio do esquema metodológico da proporcionalidade. Pretendese demonstrar que a legalidade administrativa é uma construção que depende dos setores de referência e dos bens jurídicos comprometidos pela atuação estatal e que as competências constitucionais não são estáticas ou absolutas quando se deve enfrentar circunstâncias excepcionais.

Palavras-chave: princípio de legalidade; princípio do controle; autonomia; princípio de eficácia; ordem pública; exame de proporcionalidade. 


\section{INTRODUCCIÓN}

Este artículo se origina en el trabajo académico desarrollado por el autor como profesor e investigador de las áreas de derecho administrativo y derecho laboral. Utiliza para el análisis de los casos objeto de estudio el instrumental técnico que suministra el principio de proporcionalidad, tal como lo concibe la teoría de Robert Alexy. A partir de este, pretende discutir dogmas arraigados en el derecho administrativo colombiano, justamente a partir de sus ideales fundacionales.

En efecto, desde que se declaró la emergencia sanitaria en el país, a propósito de la pandemia por la COVID-19, se ha dado un despliegue normativo sin precedentes que ha afectado a todos los sectores de la vida social. Desde el componente de la policía administrativa tendiente a la prevención y mitigación de los efectos de la enfermedad del coronavirus, por el que se han adoptado medidas en materia de orden público, especialmente relacionadas con la seguridad y la salubridad públicas; hasta el componente prestacional que ha hecho revivir la noción de un Estado interventor y de bienestar inaudito en la historia de Colombia, la cara del derecho administrativo es la más visible para explicar e interpelar esta situación de crisis y la actuación emprendida por las autoridades para enfrentarla.

En la base del derecho administrativo rondan dos grandes ideas: la protección de derechos y la satisfacción de intereses generales, que son la referencia necesaria de los tradicionales principios de control y eficacia, fundamentos para la construcción de las teorías más importantes de esta disciplina jurídica acerca de la legalidad y la responsabilidad administrativa. Estas ideas tienen la capacidad de cuestionar la acción del Estado durante la crisis y reclamar la actualidad de los pilares del Estado de derecho, esto es, la sujeción del ejercicio del poder público al orden jurídico y la efectividad de los derechos de los asociados.

Bajo la orientación de las mencionadas bases del derecho administrativo, y dentro del conjunto de situaciones que ameritarían un análisis concreto, este trabajo aborda dos problemas generados por las medidas gubernamentales tendientes a contrarrestar los efectos de la pandemia por coronavirus: la primera, la afectación al derecho de libertad de los profesionales de la salud de escoger dónde desempeñan su oficio, dada la imposición de su prestación obligatoria durante el término de la emergencia sanitaria dispuesta por el decreto Ley 538 (2020); la segunda, las posibilidades jurídicas de un manejo del orden público preferencial por parte de los alcaldes, desde las razones que suministran los principios de autonomía territorial, pluralismo, subsidiaridad y eficacia.

\section{1. ¿POR QUÉ DEBE EL DERECHO ADMINISTRATIVO INTERPELAR LA ACCIÓN DEL ESTADO DURANTE LA PANDEMIA?}

La diferencia entre el derecho administrativo y el derecho común se ha justificado tradicionalmente desde la aplicación de diversos criterios, como los relativos a los 
fines y a los medios autorizados a los sujetos jurídicos destinatarios de su regulación. Desde el punto de vista práctico, fue quizás la doctrina francesa la que mejor explicó la diferencia entre estos bloques normativos al señalar el rasgo peculiar del derecho administrativo como orden derogatorio en más y derogatorio en menos del derecho común (Rivero, 2002, p. 42).

El carácter derogatorio no supone eliminar el derecho común, sino producir su inaplicación cuando los principios de autonomía de la voluntad e igualdad no pueden operar en las relaciones entre los sujetos jurídicos. La derogación en más se expresa en el ejercicio del poder público cuando se deben satisfacer los intereses generales, para cuyo efecto las autoridades están revestidas de potestades y privilegios que afectan la denominada "paz jurídica" (García de Enterría y Fernández, 1993, p. 457).

Por su parte, la derogación en menos es la contrapartida de la anterior, pues pone de presente la idea de control del ejercicio de ese poder y establece límites a la capacidad de obrar de las autoridades con la finalidad de ajustar su acción a los derroteros de la legalidad y evitar así la arbitrariedad administrativa.

De esa manera, la llamada derogación en más se fundamenta en el principio de eficacia, mientras que la derogación en menos lo hace en el principio del control. Ambas derogaciones son dos caras de la misma moneda y expresión de la pretensión última del derecho administrativo de generar un equilibrio entre el poder y los derechos (Blanquer, 1998, p. 23), entre la autoridad y la libertad (Parejo Alfonso, 2009, p. 137).

Pues bien, el derecho administrativo inquiere sobre su misma vigencia en un contexto de situaciones excepcionales como la que ha conllevado la COVID-19, que hasta ahora se observa la faceta en más. Con base en ella, las autoridades han adoptado decisiones trascendentales que tienen una fuerte incidencia en los derechos y libertades públicas, bien sea limitándolos o promoviéndolos. Y, respecto a eso, se debe indagar por la eficacia de la acción administrativa, la buena gestión de los recursos públicos, la adecuada prestación de los servicios esenciales, la satisfacción de las necesidades básicas de la población durante la crisis, los resultados positivos en la prevención y la mitigación de los efectos del virus en la salud de los colombianos, entre otros.

Pero también debe entrar inmediatamente en juego la faceta en menos de la citada disciplina, de modo tal que se activen los mecanismos de control pertinentes en estos casos. A propósito, las autoridades deben explicar su actuación en virtud de la legalidad que la determina, esto es, sobre qué, cuánto y en qué medida tuvieron presente el marco jurídico que respalda el componente de poder público que ejercieron durante esta crisis. 


\section{LA IDEA DE CONTROL DEL PODER PÚBLICO. LA INEVITABLE CONSTRUCCIÓN DE UNA LEGALIDAD PARA LA MEDIDA QUE IMPONE EL SERVICIO OBLIGATORIO A LOS PROFESIONALES DE LA SALUD}

En los Estados de derecho no es posible activar controles de la actuación estatal sin una legalidad que la determine. Independientemente del tipo de control que se pretenda operar —administrativo, jurisdiccional, fiscal, disciplinario u otros-, el referente previo de legalidad es necesario, precisamente para evitar que esta faceta del derecho propicie lo que se quiere evitar: la arbitrariedad.

Debido a lo anterior, es preciso tener presente un detalle muy particular del derecho administrativo y de los asuntos que caben en de regulación. Se trata de asuntos que, si bien pueden suponer una estructura común de legalidad, ordinariamente revisten diferencias relevantes por los bienes jurídicos comprometidos en cada caso. Para ese efecto, no es posible asimilar los asuntos referidos a la regulación de ciertos sectores de la economía con los relacionados a la gestión de los servidores públicos, con la protección del medio ambiente o con el ejercicio del poder de policía que incide en derechos fundamentales ${ }^{1}$. El primero, por ejemplo, se construye básicamente a partir de normas internas, constitucionales, legales y reglamentarias, mientras que los demás exigen incorporar materiales normativos de otra índole y, en muchos casos, enmarcados en criterios de interpretación y aplicación especiales.

La premisa anterior plantea que muchos sectores de referencia del derecho administrativo pueden exigir la construcción de una base de legalidad diferente a la usual (Constitución, ley o reglamento). En este sentido, la hipótesis de la que parte este trabajo es que el actual contexto de la pandemia así lo sugiere, al menos al tratarse de los dos asuntos propuestos para el presente análisis. Es la única manera de establecer el tipo de reglas que debieron tomar en cuenta las autoridades para adoptar las decisiones que limitaban diversos derechos de libertad, y esa es justamente la base para su juzgamiento (Merkl, 2004, p. 472).

El marco jurídico pertinente para evaluar la legitimidad de la restricción del derecho de libertad de los profesionales de la salud a ejercer su profesión u oficio, tal como fue dispuesta por el Decreto Ley 538 (2020, art. 9), trasciende el derecho interno. Por supuesto que la fuente constitucional (art. 26) y legal (Ley 23, 1981) del referido derecho constituye la primera pieza para su análisis, pero no es suficiente. Se deben tener presentes, además, disposiciones como las previstas en los artículos 93 y 214 de la Constitución, el primero de ellos manifiesta la prevalencia en el derecho interno de los tratados internacionales sobre derechos humanos ratificados por Colombia que no sean susceptibles de suspensión en los estados de excepción; el

1 En Colombia, la doctrina (Molano López, 2005, p. 323) y la jurisprudencia (Corte Constitucional, 2003) han destacado la diferencia entre la actividad prestacional de la administración a través de la prestación de los servicios públicos y el cumplimiento de la función administrativa, esta última supone el ejercicio de autoridad con las prerrogativas que le están asociadas. Esta distinción es, sin duda, relevante para definir la legalidad a la que se someten los asuntos administrativos. 
segundo somete los estados de excepción a la regulación de una ley estatutaria, actualmente contenida en la Ley 137 de 1994.

Un análisis sistemático de las dos disposiciones constitucionales anotadas sugiere un esquema de trapecio del sistema de fuentes (Negishi, 2017) operable para el tipo de materias en cuestión, en la medida en que generan una fuerte interacción del orden interno con el orden internacional y, particularmente, con el sistema de protección de los derechos humanos. Esto supone que las medidas estatales deben adoptar un enfoque de derechos humanos y cumplir con los estándares definidos por los organismos internacionales competentes en la materia (Corte Interamericana de Derechos Humanos [CIDH], 2020).

En efecto, el derecho de los profesionales de la salud que se comenta está consagrado en los más importantes instrumentos internacionales sobre derechos humanos, entre otros, en el sistema interamericano, en la Convención Americana de Derechos Humanos (CADH) (1969, art. 6.2) y en el Protocolo Adicional a la Convención Americana de Derechos Humanos (Protocolo de San Salvador) (1988, art. 7b). Y a la luz de la idea de trabajo forzoso que supone la medida en estudio, entran en cuestión, adicionalmente, otra serie de disposiciones contenidas en estos y otros instrumentos internacionales sobre derechos humanos, como las previstas en la CADH (1969, art. 27.2), el Convenio 029 de la Organización Internacional del Trabajo (OIT, 1930) y la declaración de la OIT (1998) relativa a los principios y derechos fundamentales en el trabajo.

La entrada en escena de estas últimas disposiciones es particularmente relevante. En el artículo 27 la CADH le permite a los Estados tomar medidas especiales en situaciones de guerra, calamidades o de peligro público que amenacen su independencia o seguridad, pero, a renglón seguido, prohíbe la suspensión de ciertos derechos o el establecimiento de medidas como la esclavitud y la servidumbre (art. 27.2) (Comisión Interamericana de Derechos Humanos, 2020). El entendimiento de estos conceptos por parte de los tribunales internacionales se ha actualizado a las realidades contemporáneas, lo que ha permitido comprender situaciones en las cuales se obliga a las personas a realizar actividades bajo la amenaza de una sanción.

La Corte Interamericana de Derechos Humanos señaló que la prohibición absoluta de la esclavitud tradicional y su interpretación han evolucionado, de modo que también comprende determinadas formas análogas de ese fenómeno y, por ello, considera que la expresión del artículo 6.1 de la Convención se puede interpretar de manera amplia, a partir de lo cual incorpora la obligación de realizar trabajo para otros, impuesto por medio de coerción debido a que el "trabajo forzoso' u obligatorio designa todo trabajo o servicio exigido a un individuo bajo amenaza de una pena cualquiera y para el cual dicho individuo no se ofrece voluntariamente" (CIDH, 2016, arts. 280 y 291). 
Si la adscripción a la CADH del sentido anotado es válida, entonces el derecho de los profesionales de la salud a no ser forzados a prestar el servicio durante la pandemia de la COVID-19 es, además de un derecho fundamental y humano, uno de los que integran el denominado ius cogens (Ortiz, 2010). Esta condición les imprime una importancia jurídica superlativa en comparación con la que se reconoce a otros derechos o posiciones jurídicas, en tanto constituyen reglas consuetudinarias, esto es, expresiones del reconocimiento social de la existencia de unos valores generales, esenciales, superiores e indisponibles (Vega Ruiz y Martínez, 2002, p. 10) que se tornan imperativos y no admiten acuerdo en contrario, tal como lo prevé el artículo 53 de la Convención de Viena (1969) sobre el derecho de los tratados.

Una condición tal del derecho examinado es valorada especialmente en el artículo 93 de la Constitución nacional (1991). En esta disposición se ordena la prevalencia de los instrumentos que lo contienen sobre las normas internas, incluso las constitucionales si se tienen en cuenta los principios de pacta sunt servanda, buena fe y responsabilidad internacional, que se condensan en la fórmula prevista en el artículo 27 de la Convención de Viena (1969): un Estado parte "no podrá invocar las disposiciones de su derecho interno como justificación del incumplimiento de un tratado".

No está de más tener presente que todas las normas internacionales mencionadas hasta ahora han sido debidamente ratificadas por Colombia, esto les hace vinculantes en el derecho interno y exigibles de conformidad con sus condiciones de aplicación, en particular, el citado principio de buena fe proveniente del derecho de los tratados y el principio pro homine, por integrar el conjunto de los derechos humanos (Henderson, 2004).

Se había indicado anteriormente que, al marco jurídico de la legalidad para el problema analizado se debe incorporar la ley estatutaria 137 de 1994. Esta normativa regula los estados de excepción, entre ellos el de la emergencia económica, social y ecológica. Esta es pertinente debido a que bajo su vigencia se determinó la medida del servicio obligatorio para los profesionales de la salud.

La ley citada confirma la prevalencia en el orden interno de los tratados y convenios internacionales sobre derechos humanos ratificados por el Congreso de la República (art. 3); recuerda los derechos que, según la $\mathrm{CADH}$, son intangibles, entre ellos la prohibición de la esclavitud y la servidumbre (art. 4); prescribe que la limitación a derechos como la dignidad humana y al trabajo no puede ser tan gravosa que implique su negación (art. 5); destaca el valor hermenéutico del principio pro homine para operar las normas jurídicas que tengan que ver con la garantía de los derechos humanos (art. 4, inc. final); y, finalmente, ordena que las facultades del Gobierno nacional durante los estados de excepción deben ser utilizadas cumpliendo siempre con los principios de finalidad, necesidad, proporcionalidad, motivación, así como de acuerdo con las condiciones y requisitos a los cuales se refiere esta ley (arts. 9-14). 
Es necesario reparar la prescripción de esta ley con respecto al modo en el que está ordenado el establecimiento de limitaciones a los derechos y libertades públicas. La norma expresa, reiteradamente, que se debe hacer sobre la base de la finalidad, necesidad, motivación y proporcionalidad. Esto sugiere, además de todo lo anterior, que en este escenario, los modos de interpretación y aplicación del derecho no necesariamente van a ser los tradicionales criterios de temporalidad, especialidad o jerarquía que se utilizan ordinariamente para la determinación de las normas aplicables a los casos concretos, sino que se deberá apelar a instrumentos que formenten la ponderación de los derechos y las potestades que entran en juego.

A este respecto, no se debe perder de vista que cuando se trata de situaciones de extremada urgencia, como la generada por la COVID-19, la tensión entre los derechos y las potestades públicas es notoria. En el caso propuesto, entre el derecho de los profesionales de la salud a escoger cuándo, cómo y dónde prestan sus servicios y la potestad del Estado de exigirlo, dada la gravedad de la pandemia y la crisis sanitaria generada y que requiere personal calificado.

Lo anterior pone de manifiesto la posibilidad de que en este tipo de contextos se presenten los llamados "casos difíciles" (Navarro, 1993), es decir, aquellos para los cuales: i) no existe una disposición que regule el caso planteado; ii) existe una norma que regula claramente el caso, pero se estima injusta o claramente perjudicial; iii) existen normas aplicables que aquejan gran indeterminación o ambigüedad; iv) existe más de una disposición aplicable al caso, pero cada una de ellas establece soluciones diferentes; v) existen precedentes, pero a la luz del caso, se deben modificar (Lopera y Arias, 2010, p. 107).

En otras palabras, el uso de la proporcionalidad es prácticamente inevitable. No solo es el método más ventajoso para el control de los actos de intervención en los derechos fundamentales y para la definición de los contenidos vinculantes que derivan de esta clase de derechos (Bernal Pulido, 2007, p. 492), sino que también es el instrumento que apoya el trabajo de control de muchos tribunales constitucionales del mundo, entre ellos el colombiano y de cortes internacionales como la Corte Interamericana de Derechos Humanos (Clérico, 2015), para resolver las disputas que enfrentan los derechos entre sí o entre estos y los intereses públicos (Stone Sweet y Matthews, 2013, pp. 11-19).

Son muchos más los referentes de legalidad que se pueden esgrimir alrededor del problema en cuestión, provenientes, fundamentalmente, del derecho internacional y específicamente del regulatorio de los derechos humanos. Pero los citados son suficientes para advertir dos cosas. La primera es que la legalidad es un marco normativo que exige ser elaborado sobre la base concreta de los bienes jurídicos o derechos que entran en la esfera de actuación del Estado, esto hace que esa labor ofrezca referentes 
de legalidad diferentes, no estáticos, dada la variedad que revisten esos bienes y los contextos en los que se puede producir su afectación.

La segunda es que esa legalidad cumple una doble función en los procesos de operación del derecho: por un lado, sirve para encauzar la producción normativa, es decir, la que se expresa en el establecimiento de reglas, mandatos y órdenes de conformidad con la competencia que se haya reconocido a las autoridades; por el otro, suministra el referente para interpretar y aplicar tales normas a la hora de efectuar el control de las medidas adoptadas.

Para el caso concreto, el primero de estos procesos es predicable por el Gobierno nacional desde que estableció el servicio obligatorio de los médicos durante la pandemia; el segundo, por quienes tienen la función de juzgar dicha medida, por ejemplo, los jueces de la república que tengan a su cargo la revisión de su constitucionalidad. El marco de referencia, se insiste, es el mismo para ambos casos.

\section{LA IDEA DE LA SATISFACCIÓN DE LOS INTERESES GENERALES. LA COMPETENCIA PARA EL MANEJO DEL ORDEN PÚBLICO EN CLAVE DE AUTONOMÍA TERRITORIAL, PLURALISMO, SUBSIDIARIDAD Y EFICACIA}

\subsection{E marcojuńdcogenerd del manjodal ordenpúblicoen Clombia}

Se entiende el orden público como "el conjunto de condiciones de seguridad, tranquilidad y salubridad que permiten la prosperidad general y el goce de los derechos humanos" (Sentencia C-435/13, 2013). Eso indica que se trata de uno de los denominados conceptos jurídicos indeterminados (García de Enterría y Fernández, 1993) que, al comprender aspectos tan disímiles como los anotados, en procura de la satisfacción de los intereses generales, siempre deja la inquietud acerca de su contenido y alcances, mucho más cuando su invocación es una potestad de autoridades administrativas y que, usualmente, sirve como medio para la restricción de derechos fundamentales.

La Constitución Política de Colombia atribuye la potestad del manejo del orden público a varias autoridades: al presidente de la República (art. 189.4), a los gobernadores (art. 303) y a los alcaldes (art. 315.2). Estas autoridades se hallan, en este contexto, en una relación de jerarquía secuencial que permite formular la regla de la prevalencia de las decisiones del presidente en todos los casos, tal como también lo prevé el artículo 296 de la Constitución y lo ha reconocido la jurisprudencia constitucional (Sentencia C-189/19, 2019).

A su vez, el Código Nacional de Policía y Convivencia Ciudadana (Ley 1801, 2016, arts. 199 ss.) prescribe, de modo más detallado, las funciones de las citadas autoridades, reitera la prevalencia de la competencia del presidente sobre los gobernadores y de la de estos sobre la de los alcaldes. No obstante, reconoce en el artículo 202 a los gobernadores y alcaldes como competencias especiales de policía 
cuando deban atender circunstancias excepcionales. En este sentido, determina sobre el particular lo siguiente:

Competencia extraordinaria de policía de los gobernadores y los alcaldes, ante situaciones de emergencia y calamidad. Ante situaciones extraordinarias que amenacen o afecten gravemente a la población y con el propósito de prevenir el riesgo o mitigar los efectos de desastres, epidemias, calamidades, situaciones de inseguridad y disminuir el impacto de sus posibles consecuencias, estas autoridades podrán ordenar, en su respectivo territorio, las siguientes medidas con el único fin de proteger y auxiliar a las personas y evitar perjuicios mayores: $[\ldots]$

4. Ordenar la suspensión de reuniones, aglomeraciones, actividades económicas, sociales, cívicas, religiosas o políticas, entre otras, sean estas públicas o privadas.

5. Ordenar medidas restrictivas de la movilidad de medios de transporte o personas, en la zona afectada o de influencia, incluidas las de tránsito por predios privados.

6. Decretar el toque de queda cuando las circunstancias así lo exijan.

7. Restringir o prohibir el expendio y consumo de bebidas alcohólicas.

8. Organizar el aprovisionamiento y distribución de alimentos, medicamentos y otros bienes, y la prestación de los servicios médicos, clínicos y hospitalarios.

9. Reorganizar la prestación de los servicios públicos.

Ahora bien, el manejo del orden público es uno de los pocos asuntos en los que la regla de la jerarquía entre los niveles nacional y territorial se parece mantener. Cabe recordar que, por disposición del artículo 388 de la Constitución, las relaciones entre los aludidos niveles territoriales deben operar de conformidad con los principios de coordinación, concurrencia y subsidiariedad, en los términos que establezca la ley, una lógica consecuencia de la autonomía reconocida a los territorios para la gestión de sus propios intereses (Sentencia SU-095/18, 2018).

El sentido natural de los principios de la organización territorial colombiana enunciados parten justamente de la noción contraria a la jerarquía y promueven, más bien, la idea de que el ejercicio de las competencias se debe activar, de preferencia, por parte de las autoridades que representan "el nivel más próximo al ciudadano, lo cual es expresión del principio democrático y un criterio de racionalización administrativa, en la medida en que son esas autoridades las que mejor conocen los requerimientos ciudadanos" (Sentencia C-149/10, 2010).

De esto se desprende que las autoridades locales son llamadas a definir, en primera instancia y de modo prevalente, los asuntos que corresponden a sus comunidades, y que las autoridades de los niveles nacional y territorial deben actuar cuando aquellas se muestren incapaces o sean ineficientes para llevar a cabo sus responsabilidades. 
Algunos incluso han visto en los principios de la organización territorial mencionados una especie de proceso de federalismo atenuado (Molina, 2004).

La jurisprudencia ha señalado a este respecto que:

[L]a territorialidad y [l]a unidad nacional [son] dos elementos teleológicamente inescindibles, ontológicamente diferenciables a partir de su materialidad geográfica, con unos destinatarios comunes -los habitantes del país-, y por entero, instancias orgánicas y funcionales de un mismo mecanismo estatal: el de la República unitaria, descentralizada, con autonomía de sus entidades territoriales, democrática, participativa y pluralista. (Sentencia C-127/02, 2002)

Y ha agregado que:

De esta manera, la autonomía actúa como un principio jurídico en materia de organización competencial, el cual debe realizarse en la mayor medida posible teniendo en cuenta la importancia de los bienes jurídicos. Adicionalmente, tiene un carácter vinculante y obligatorio, por lo que las responsabilidades de las entidades territoriales deben ser asumidas por ellas mismas, sin desconocerse el apoyo que les puedan brindar las autoridades nacionales. (Sentencia SU-095/18, 2002)

El anterior cuadro competencial pone de manifiesto que, para el manejo del orden público, la preferencia que plantean varias normas constitucionales a favor del presidente de la República es provisional, esto es, prima facie, en relación con los gobernadores y los alcaldes. Ese carácter implica que no es una prevalencia absoluta y que otras razones constitucionales, de mayor peso, pueden proponer lo contrario si se analizan las circunstancias de los casos concretos en los que tales medidas pretenden operar. Esas razones, se considera, son suministradas por los principios de autonomía, pluralismo, eficacia y subsidiaridad.

\subsection{Interesesgenerdesyorden púdica la legitimacónparasucantreión}

El orden público es una manifestación "concreta" de los llamados intereses generales, pilar de la organización estatal e institución medular del derecho público moderno y del derecho administrativo en particular (Escola, 1989, p. 31). El concepto de intereses generales ha ganado gran protagonismo en el marco de los Estados sociales de derecho hacia los cuales tiende el constitucionalismo contemporáneo. Se estima que alrededor de su estudio se han construido las principales teorías del derecho administrativo (servicio público, acto administrativo, responsabilidad pública, obra pública, entre otras) (Conseil D'Etat, 1999), lo que muestra la verdadera dimensión del bien colectivo que respalda la actuación de las autoridades cuando lo invocan.

Ahora bien, como ocurre con los conceptos básicos del derecho, en los que la importancia de las instituciones claves no se corresponde necesariamente con la claridad de sus líneas fundamentales, el interés general está lejos de tener una definición concreta (Rekosh, 2005, pp. 166-179). A pesar de los rigurosos estudios que lo han 
abordado (Bitonti, 2011), ni la ciencia ni la dogmática del derecho han podido clarificar hasta el momento qué es el interés general, más allá de develar su equivalencia con otros conceptos normativos que pueden tener similar alcance, como es el caso del interés público, el bienestar general, el bien común, la utilidad pública y, en otros momentos, con la razón del Estado, la libertad y la igualdad (Montalvo, 2011).

Pero, más que dar cuenta de una definición del concepto, lo que importa es establecer la forma en la que se pueda determinar lo que hay que entender por interés general y sus manifestaciones, en cada uno de los sectores en los que actúa el Estado. Y en ese sentido, la idea planteada por Vedel (1980, p. 258) es ilustrativa en el sentido de que se trata de un concepto estrictamente jurídico que, necesariamente, implica el elemento competencial, es decir, la estipulación del órgano o conjunto de órganos a los que se les ha otorgado la potestad de establecer qué se debe considerar como tal.

Si bien por el principio democrático, el legislador es el primer llamado a definir el contenido del interés general, no se puede olvidar que la administración es la titular por excelencia para su satisfacción, según lo proclama el artículo 209 de la Constitución Política. Eso la legitima para participar en su conformación, teniendo en cuenta, además, que a partir de la fórmula de la descentralización territorial y administrativa que consagra la Constitución y de la representación democrática que allí verifica, a través de órganos y autoridades ejecutivas elegidas popularmente (Robledo Silva, 2006), esa competencia de definición se traslada también a los distintos niveles de la administración pública.

Y hay algo más. La relatividad del interés general se acrecienta en estos casos por el pluralismo ideológico y político subyacente a la Constitución de 1991 (Sentencia C-018/18, 2018), lo que puede implicar - como de hecho ocurre actualmente- que el manejo de los asuntos del Estado en sus distintos niveles (nacional, departamental, distrital o municipal) esté a cargo de dirigentes políticos de diferentes vertientes ideológicas y con nociones diferentes acerca de los intereses generales que pretenden promover.

Ello implica que en las democracias pluralistas —inevitablemente - se deba desentrañar el interés público de modo diferenciado (Haberle, 2007, p. 378), es decir, lo que se pueda concebir de tal manera depende en cada momento de las concepciones dominantes acerca de los fines del Estado y la manera como deben ser satisfechos (Garrido Falla, Palomar Olmeda y Losada Angel, 2006, p. 65).

A partir de las consideraciones anteriores, cabe insistir en que una de las manifestaciones más importantes de los intereses generales es el orden público. Lo que se ha dicho respecto a aquellos es aplicable a este de igual manera. Es tan indeterminado o ambiguo, que ha sido considerado uno de los conceptos más polivalentes del vocabulario jurídico, que se caracteriza por la mutación de su significado en función del sector del ordenamiento en el que aparece y de la época en la que se le pretenda 
aplicar, por no decir que es altamente sensible al tipo de ideología de la administración que ostente el Gobierno en cada momento. En la ambigüedad se encuentra su característica más fuerte, por lo cual se deduce un fuerte paralelismo con la figura del interés general (Montalvo Abiol, 2010).

En Colombia ha habido una cierta concordancia jurisprudencial acerca de que el orden público comprende campos como la seguridad, la tranquilidad y la salubridad públicas (Sentencia C-435/13, 2013). Ese hecho no le resta dificultades a su comprensión, mucho más cuando el elemento competencial que, como se dijo, es la base para su conformación o definición, está repartido entre diferentes autoridades del Estado de diverso nivel administrativo, a quienes respaldan los principios de autonomía territorial, pluralismo, eficacia y subsidiaridad.

Con base en los aludidos principios es posible afirmar que los alcaldes tienen competencia para apreciar, definir y declarar lo que es de orden público en sus respectivas localidades, y que esa competencia tiene todas las condiciones para prevalecer sobre la que efectúan otras autoridades, por los menos en contextos de emergencia como la que propone la pandemia de la COVID-19 y en tanto obren con mayor eficacia que aquellas. Esta tesis se desarrolla más en adelante.

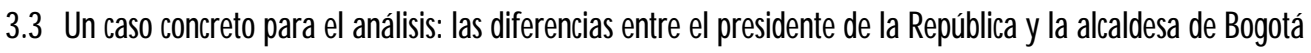 acercadd alcancedelasmeddaschaisamiertoddigatriod dratela energeniasanitaria}

El Decreto 457 emitido por el Gobierno nacional el 22 de marzo de 2020, ordenó el aislamiento preventivo obligatorio de todas las personas habitantes de Colombia, por efecto de la emergencia sanitaria causada por la COVID-19. Esta medida fue prorrogada en varias oportunidades, entre otras, en virtud de los decretos 593 y 636 del mismo año. En el primero de estos decretos se dispuso la limitación total de la libre circulación de personas y vehículos en el territorio nacional, con las excepciones previstas en el artículo 3. En los dos últimos se extendió la excepción a otros sectores económicos como manufactura, construcción, automotores, lavanderías, comercio al por mayor de muebles y enseres domésticos, entre otros, a los cuales se les habilitó nuevamente para trabajar presencialmente con las medidas de seguridad requeridas en el marco de una estrategia denominada "aislamiento inteligente".

La alcaldesa de Bogotá se ha opuesto a la aludida estrategia al afirmar que "la prioridad no son las empresas o cómo vaya la economía, sino la salud de los ciudadanos". Y ante la propuesta del presidente del aislamiento inteligente, señaló que "lo único inteligente es quedarse en casa" (Semana, 2020b). Recientemente sostuvo:

Aquí lidero la ciudad capital con un gobierno de centro izquierda frente a un gobierno nacional de derecha, donde la presión es volver a la normalidad, volvamos a producir, volvamos al empleo, es que vamos a perder más vidas por el hambre que por la pandemia [...] volvamos, volvamos, volvamos. (Noticias Caracoltv, 2020) 
Informó por ello la funcionaria que la "manufactura no entrará el lunes [27 de abril] en Bogotá porque no estamos preparados; yo me enteré antier por una alocución presidencial, pero se tienen que tomar medidas", afirmó la mandataria capitalina. Para la alcaldesa López, "es muy fácil sacar un decreto que dice que se abra la manufactura. Pero no es lo mismo en el Chocó que en Bogotá, que tiene millones de personas y que además tiene el mayor número de casos contagiados". Insistió en que el retorno de sectores a trabajar será gradual: "hacer decretos es fácil, pero a los alcaldes nos toca ejecutar, hacer los planes, organizar" (Angarita, 2020).

Ante posiciones como estas, los decretos 457, 593 y 636 de 2020, después de recodar que los gobernadores y alcaldes son agentes del presidente de la República en materia de orden público, determinaron que la violación e inobservancia de las medidas e instrucciones adoptadas por este dará lugar a la aplicación de las sanciones correspondientes a los gobernadores y alcaldes que omitan su cumplimiento. La pregunta que surge alrededor de esta y otras situaciones en el manejo del orden público durante la pandemia es si los alcaldes tienen la facultad de definir medidas de orden público, concretamente para prevenir y mitigar los efectos de la enfermedad por coronavirus en sus territorios y apartarse así de las directrices del presidente de la República.

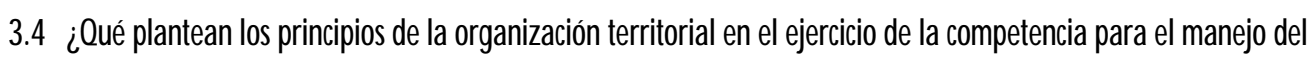 ordenpúdico?}

El marco jurídico descrito en el apartado 3.1 de este trabajo propone un panorama en el que es lógico pensar en que los alcaldes, si bien son estimados como primeras autoridades de policía en sus respectivos municipios, en virtud de lo cual son responsables de la preservación del orden público y pueden expedir por ello reglamentos, órdenes, mandatos y, en general, dictar según las circunstancias del caso las medidas indispensables para el mantenimiento del orden público, no dejan en todo caso de ostentar la calidad de agentes del presidente de la República o del respectivo gobernador para esos mismos efectos, tal como lo reconoció la Sala de Consulta y Servicio Civil del Consejo de Estado (Radicación 892, 1996).

Una mirada general como esta puede ser correcta desde disposiciones específicas de la Constitución, como las previstas en los artículos 296, 303 y 315.2, pero discutible desde las bases de su esquema territorial, en el que la autonomía, descentralización y subsidiaridad tienen mucho que decir, y por supuesto desde los principios de la función administrativa declarados en el artículo 209, particularmente el de eficacia.

En efecto, de la descentralización se desprende que los entes territoriales reciben sus funciones y atribuciones del poder central para que las ejerzan con un amplio grado de libertad, a fin de procurar la eficiencia de la administración 
(Sentencia C-624/13, 2013). De la autonomía surge un verdadero poder de dirección política que radica en las mismas comunidades locales para que, a través de sus propias autoridades, establezcan sus prioridades de desarrollo y se atienda a sus necesidades (Sentencia C-534/96, 1996). Desde la subsidiaridad — que quizás tiene una relación más estrecha con la descentralización— se ordena que las decisiones se adopten de conformidad con el "principio de proximidad" o "principio de cercanía" al ciudadano (Sentencia C983/05, 2005), esto es, que la competencia la deba asumir el nivel de gobierno más eficiente y que esté lo más cerca posible de las personas (Duque Cante, 2017).

Ya se dijo que los alcaldes están facultados para apreciar las condiciones de orden público en sus respectivas jurisdicciones y declarar las medidas pertinentes para su conservación. Es una de las tantas competencias que se les ha asignado como autoridades ejecutivas de los municipios, esto es, sus máximos representantes y quienes, acompañados de los concejos municipales, ejercen los derechos y funciones propios de la autonomía territorial reconocida en el artículo 287 de la Constitución.

La Corte Constitucional ha señalado en dicha disposición que se fija, en doble sentido, lo que constitucionalmente corresponde a la autonomía garantizada de las entidades territoriales. Por una parte, garantiza la gestión de sus intereses, es decir, los de la colectividad correspondiente; por otra parte, implica contenidos mínimos que deben respetar las autoridades nacionales en sus relaciones con las entidades territoriales, como es el caso de sus derechos al autogobierno, a ejercer las competencias que les correspondan y a administrar los recursos necesarios para el cumplimiento de sus funciones (Sentencia C-189/19, 2019).

En la decisión a la que se hace mención en el párrafo anterior la Corte afirma que el autogobierno se caracteriza especialmente por la falta de subordinación de los alcaldes a las autoridades nacionales, excepto en temas específicos como el manejo del orden público. Aun así, en otras providencias ha señalado que en todas las materias en las que concurren intereses nacionales e intereses locales no se puede eliminar el contenido básico de la autonomía, pues al ser esta un principio jurídico en materia de organización competencial se debe realizar en la mayor medida posible debido a la importancia de los bienes jurídicos. Eso indica que la autonomía tiene un carácter vinculante y obligatorio, y exige que las responsabilidades de las entidades territoriales se asuman preferentemente por ellas mismas, sin desconocer la posibilidad de intervención de las autoridades nacionales (Sentencia SU-095/18, 2018).

Entonces, como ya se había dicho, lejana está la posibilidad de asumir la prevalencia del presidente de la República sobre los alcaldes en materia de orden público como regla definitiva. Los bienes jurídicos comprometidos y las circunstancias en que ellos se deben garantizar pueden suministrar razones de mayor peso para que las decisiones locales sean preferentes en la materia referida. 
Este panorama propone un escenario de posibilidades jurídicas que se debe examinar desde los derroteros del principio de proporcionalidad, como en efecto lo avala la jurisprudencia constitucional colombiana y reclama que las medidas que restringen la autonomía de las entidades territoriales deben pasar por el riguroso examen de los tres subprincipios que integran este instrumento, esto es, los de idoneidad, necesidad y proporcionalidad en sentido estricto (Sentencia C-358/17, 2017).

No es este el lugar para efectuar un análisis de esa envergadura, ello rebasaría los propósitos de este texto. Más bien, se pretende aportar elementos para que un examen de proporcionalidad en estos casos tenga en cuenta premisas sólidas y ofrezca justificaciones razonables al juicio de prevalencia con el que se intenta solucionar las tensiones entre los intereses nacionales y los territoriales comprometidos en el complejo manejo del orden público.

\subsection{B exaren de proporionalidad y los aportes de los pinipios de purdisno y eficaia en la

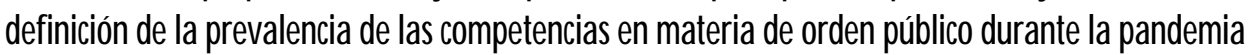 celaCOVD19}

3.5.1 El presupuesto de cualquier examen de proporcionalidad, como se dijo antes, es la existencia de casos difíciles. Cuando la jurisprudencia afirma que en los eventos de tensión entre los intereses nacionales y los territoriales, el principio de autonomía se debe realizar en la mayor medida posible, apela a un concepto teórico, el de "mandato de optimización" (Alexy, 2008, p. 80). Este concepto representa una convención interpretativa que permite hablar de principios en tanto normas que no permiten un razonamiento aislado sino en conjunto con otras normas y que, por lo mismo, están ligados a la idea de conflictos normativos (Lopera Mesa, 2006, p. 131).

En este evento en particular entran en tensión la facultad preferente que, en materia de orden público, tiene el presidente de la República sobre los gobernadores y alcaldes prevista — entre otros - en el artículo 296 de la Constitución, y la autonomía reconocida a los municipios, prevista en el artículo 287 de la misma Constitución, que les permite a los alcaldes adoptar decisiones en esa materia como parte de la gestión de los propios intereses de sus comunidades. Existen buenas razones de parte y parte para encontrar una solución, pero serían incompatibles si se aplican al mismo tiempo.

En esta tensión se pueden presentar variables relevantes. La primera, aquella en la que las medidas de orden público de ambas autoridades procuran garantizar el mismo elemento del orden público, concretamente la salubridad pública que, a la postre, implica la protección de la salud, prevista como derecho, como servicio público y como deber del Estado en el artículo 49 de la Constitución. Esta variable se puede ubicar en primera fase de la atención de la pandemia y se evidencia en normativas como el Decreto 457 de 2020. En estos casos, el examen de proporcionalidad exige un análisis más enfocado en los subprincipios de la idoneidad y la necesidad. 
El de idoneidad indaga por el conjunto de medidas más adecuado para prevenir, enfrentar y mitigar los efectos de la enfermedad por coronavirus, caso en el cual los contextos en los que deben regir dichas medidas son definitivos, la frase de la alcaldesa de Bogotá en el sentido de que "no es lo mismo en el Chocó que en Bogotá" es muy diciente al respecto. El de necesidad verifica, además de la adecuación de las medidas, el grado de restricción que suponen para los derechos comprometidos. Se parte de la idea de que la proporcionalidad tiene que ver, en gran parte, con la aplicación de la alternativa que suponga menos daños.

La segunda variable es aquella mediante la cual se procuran garantizar diferentes elementos del orden público o la satisfacción — a la par- de derechos fundamentales de las personas. Este escenario se ubica en la segunda fase de la atención de la pandemia en Colombia y que se ha denominado "aislamiento inteligente". Se evidencia en normativas como el Decreto 593 de 2020, en el que, además de adoptar medidas para la protección de la salud, se disponen otras para garantizar, parcialmente, el derecho al trabajo y a la libre empresa.

Esta variable en particular pone en tensión las medidas de aislamiento para la protección del derecho a la salud con la realización de otros derechos protegidos constitucionalmente, lo que sin duda puede llevar el examen de proporcionalidad a la etapa de la proporcionalidad en sentido estricto, al hacerse indispensable sopesar las razones en juego y ponderar el grado de importancia de la protección de esos bienes con el grado de afectación de los otros.

3.5.2 Otro presupuesto del examen de proporcionalidad es la legitimidad. Este es un punto que no amerita mayores comentarios al tratarse del caso en cuestión, pues la finalidad de las medidas adoptadas por el presidente y por los alcaldes —ante todo para proteger el derecho a la salud - están respaldadas por la Constitución en las normas antes señaladas. Cabe anotar que las variables que se mencionaron en el punto anterior no modifican esta valoración, ya que la consecución de otros bienes jurídicos, como el derecho al trabajo y libertad de empresa, también están autorizados por la Constitución Política.

3.5.3 El pluralismo, que está consagrado como principio del Estado colombiano en el artículo 1 de la Constitución Nacional, expresa la idea de respeto por las opciones ideológicas, demanda a las organizaciones políticas la canalización de sus ideas a través de los procedimientos democráticos previstos en la Constitución, puesto que "Ie]n los [E]stados contemporáneos la voz del pueblo no puede ser apropiada por un solo grupo de ciudadanos, así sea mayoritario, sino que surge de los procedimientos que garantizan una manifestación de esa pluralidad" (Sentencia C-018/18, 2018).

Tanto el presidente de la República como los mandatarios municipales tienen una legitimidad democrática de similar origen, con la diferencia de que operan en diferentes niveles administrativos del Estado. Ambos expresan opciones ideológicas y políticas 
que tuvieron el favor popular y que, por ello, son legítimas y pueden coexistir dentro de la vida institucional colombiana. Desde esta perspectiva, el principio democrático difícilmente puede ser un factor de desequilibrio para la tensión que se presenta entre los intereses nacionales y los municipales.

Es legítimo que en el contexto de una pandemia, el presidente de la República procure garantizar el derecho a la salud, a la par con derechos como el trabajo y la libertad de empresa, y que los alcaldes — como en el caso de Bogotá- pretendan proteger sobre todo el derecho a la salud. El problema es determinar cuál es la finalidad que debe primar y las medidas más eficaces para enfrentar una situación como la actual que, si bien ha incidido en múltiples bienes y derechos, es de tal gravedad e intensidad que ha puesto en riesgo la salubridad pública, el derecho a la salud y el mismo derecho a la vida de los colombianos.

3.5.4 La jurisprudencia ha planteado que la eficacia es una cualidad de la acción administrativa que impone deberes y obligaciones a las autoridades para garantizar la adopción de medidas de protección de los derechos, especialmente de las personas en situaciones de vulnerabilidad. Es por esa razón que sostiene una especial relación con el principio de eficiencia, según el cual el Estado debe lograr maximizar y racionalizar la relación costos-beneficios, de manera que obtenga el mayor rendimiento o los resultados con menores costos (Sentencia C-826/13, 2013). La efectividad de los derechos se desarrolla con base en esas dos cualidades: eficacia relativa al cumplimiento de las determinaciones de la administración y eficiencia relacionada con la elección de los medios más adecuados para el cumplimiento de los objetivos (Sentencia T-068/98, 1998).

En relación con cada uno de los bienes jurídicos que se pretendan garantizar, la comparación de la eficacia y eficiencia a la hora de enfrentar la pandemia puede obtener valoraciones diferentes, tanto de los expertos en el tema como de los ciudadanos, quienes califican a sus mandatarios de conformidad con muchos parámetros. Por ejemplo, durante lo que va de la emergencia, los alcaldes han obtenido calificaciones muy altas por el tipo de medidas adoptadas. Algunos han sobresalido debido a que sus determinaciones han sido estimadas como adecuadas, necesarias y exitosas. Ese es el caso de Bogotá (El Tiempo, 2020; Semana, 2020c).

En un análisis del portal La Silla Vacía (Ardila, 2020) se refleja la tensión, pero también la percepción de la eficacia de las decisiones de los alcaldes:

En un país históricamente centralista y presidencialista, como nunca son ellos hoy la cara del Estado que resurge y está llamado a resolver localmente las urgencias de la crisis sanitaria:

Alistan los hospitales, determinan las condiciones del transporte público, entregan las ayudas en mercados y, en general, tienen que volver prácticas en 
terreno todas y cada una de las decisiones que la tecnocracia define en escritorios en Bogotá, un asunto que siempre ha sido complejo.

Los gobernadores también, pero, por su cercanía a la gente, sobre todo se sienten los alcaldes.

La más mediática - por las razones obvias de su cargo, por su reconocimiento y porque tiene que lidiar con casi la mitad de los contagios de toda Colombia- es la alcaldesa de Bogotá Claudia López, quien tiene un ya conocido contrapunteo con el lp|residente y cuyo partido le hace oposición al Gobierno Nacional.

Pero en todas las regiones hay ejemplos de mandatarios que, sin necesariamente ser de oposición o contar con la misma influencia o tono, toman medidas más allá de las de Duque, hacen reclamos e inquieren altos funcionarios del centro incluso sin la tradicional intermediación de los congresistas que fungen como sus jefes políticos.

La situación no s|ollo evidencia una novedad — probablemente temporal—en la dinámica del poder, sino que parece en contravía de los deseos originales del Gobierno, que al principio de la emergencia (cuando varios dispusieron acciones más propias de un estado federal, como el cierre de fronteras de departamentos) sacó un decreto básicamente para recordar que sus decisiones en el orden público priman sobre las de gobernadores y alcaldes.

Casi mes y medio después, el [p|residente reconoce y comparte abiertamente la responsabilidad de las medidas contra [la enfermedad por] coronavirus con los mandatarios locales, como pasa en este momento con la extensión de la cuarentena nacional con reapertura gradual de los sectores de la construcción y manufactura, que terminó desacelerada justamente por las disposiciones particulares de cada alcalde.

Por supuesto que la anterior es una valoración general. En el caso de la alcaldesa de Bogotá, sus decisiones han estado sustentadas en un equipo técnico muy calificado (Hernández, 2020) y han sido compartidas, incluso, por organismos internacionales reconocidos como autoridad en el manejo de la pandemia (Semana, 2020a).

Desde la perspectiva de la eficacia sobre la que interpela el derecho administrativo a las autoridades en el contexto de la pandemia de la COVID-19, estas percepciones, justificaciones técnicas y el conocimiento directo del contexto social, económico y cultural que los alcaldes tienen sobre las comunidades en las que deben operar las medidas de orden público, favorecen su posición en un examen de proporcionalidad, sobre todo cuando se trata de los juicios de necesidad y de proporcionalidad en sentido estricto, en este último se hace imperiosa la pregunta por la certeza empírica y epistémica de las premisas que sustentan decisiones que conllevan la afectación de bienes y derechos constitucionales (Alexy, 2002, p. 56).

Quizás por eso la previsión — reseñada más atrás— del Código Nacional de Policía y Convivencia Ciudadana (Ley 1801, 2016, art. 202) tiene sentido cuando favorece la competencia de los alcaldes en situaciones extraordinarias que amenacen o afecten 
gravemente a la población, con la finalidad de prevenir el riesgo o mitigar los efectos de desastres, epidemias, calamidades, situaciones de inseguridad y disminuir el impacto de sus posibles consecuencias en sus respectivos territorios. A diferencia de los asuntos que tienen que ver con el mantenimiento y restablecimiento de la convivencia, respecto a la cual deben observar las instrucciones del presidente de la República, según lo dispone el artículo 205.16 del citado Código, la facultad contenida en el artículo 202 se estructura legalmente con cierta autonomía.

El detalle de esta estructuración competencial consiste en que las facultades invocadas por el presidente de la República para el manejo del orden público durante esta pandemia, tal como se registra en los decretos 457, 593 y 636 de 2020, se estableció en el artículo 189.4 y no en ejercicio de facultades legislativas por efectos de la emergencia económica, social y ecológica decretada, según lo dispuesto en el artículo 215 de la Constitución. Se trata así de una competencia presidencial subordinada a la ley y esta, como se ha visto, les entregó directamente a los alcaldes el manejo de las situaciones extraordinarias relacionadas con calamidades y emergencias como la que vive actualmente el país.

\section{CONCLUSIONES}

La pandemia de la COVID-19 revitalizó los tradicionales roles de autoridad y prestacional de los Estados contemporáneos. Esa circunstancia da vigencia al derecho administrativo y a sus ideas básicas de control y eficacia, esto es, las que se asocian con la protección de los derechos y la satisfacción de los intereses generales. El papel de esa disciplina jurídica, en un contexto de excepción como ese, es interpelar a las autoridades por el cumplimiento de estos ideales.

El control de cualquiera de las actuaciones del Estado supone una correspondencia necesaria a la legalidad. Esta legalidad no es estática, se debe construir o reconstruir a partir de los bienes jurídicos o los derechos comprometidos en cada caso, según sea el sector de referencia en el que incida el Estado. Los estados de excepción, como la emergencia económica, suponen un marco jurídico de legalidad que trasciende el orden interno e involucra, incluso, el sistema internacional de los derechos humanos; es el caso concreto examinado del servicio obligatorio impuesto al personal de la salud mediante el Decreto Legislativo 538 de 2020.

El manejo del orden público está lejano de ser una competencia siempre preferente del presidente de la República. En circunstancias excepcionales como las presentadas durante la pandemia de la COVID-19, los principios de autonomía, eficacia, subsidiaridad y pluralismo observados desde la perspectiva de un examen de proporcionalidad, así como también las normas legales vigentes, sugieren la preferencia por la competencia local con la excepción de los asuntos relacionados con la convivencia social. 


\section{REFERENCIAS}

Alexy, R. (2002). Epílogo a la teoría de los derechos fundamentales. Revista Española de Derecho Constitucional, (66), 13-64.

Alexy, R. (2008). Teoría de los derechos fundamentales (2 ed.). Centro de Estudios Políticos y Constitucionales.

Angarita, J. R. (2020, 22 de abril). El sector de la manufactura no entrará a trabajar el lunes en Bogotá: Claudia López. RCN Radio. https://www.rcnradio.com/bogota/el-sector-de-la-manufactura-no-entraratrabajar-el-lunes-en-bogota-claudia-lopez

Ardila Arrieta, L. (2020, 30 de abril). Los alcaldes se crecen frente a Duque en tiempo de virus. La Silla Vacía. https://lasillavacia.com/los-alcaldes-se-crecen-frente-duque-tiempo-virus-76458

Asamblea Nacional Constituyente (ANC) (1991). Constitución política de Colombia (2 ed). Legis.

Bernal Pulido, C. (2007). El principio de proporcionalidad y los derechos fundamentales. El principio de proporcionalidad como criterio para determinar el contenido de los derechos fundamentales vinculante para el legislador. Centro de Estudios Políticos y Constitucionales.

Bitonti, A. (2011). Considerazioni Teoretiche sul Concetto di Interesse Pubblico. Universitá degli Studi Roma Tre.

Blanquer, D. (1998). Introducción al derecho administrativo. Tirant lo Blanch.

Clérico, L. (2015). Hacia la reconstrucción de un modelo integrado de proporcionalidad a la luz de la jurisprudencia de la Corte Interamericana de Derechos Humanos. En J. Fabra Zamora y L. García Jaramillo (eds.), Filosofía del derecho constitucional, Cuestiones fundamentales (pp. 431-451). UNAM.

Comisión Interamericana de Derechos Humanos. (2020, 10 de abril). Resolución 1. Pandemia y derecho humanos en las Américas.

Congreso de la República de Colombia. (2016, 29 de julio). Ley 1801 de 2016. Código Nacional de Seguridad y Convivencia Ciudadana. Diario Oficial n. ${ }^{\circ} 49.949$.

Conseil D’Etat. (1999). Réflexions sur l'interet général. Rapport public, Paris.

Consejo de Estado (1996, 6 de septiembre). Radicación 892. Sala de Consulta y Servicio Civil (Roberto Suárez Franco, C. P.). https://www.funcionpublica.gov.co/eva/gestornormativo/norma.php?i=3829

Corte Constitucional. (1996). Sentencia C-534/96 (Fabio Morón Díaz, M. P.). https://www. corteconstitucional.gov.co/relatoria/1996/C-534-96.htm

Corte Constitucional. (1998). Sentencia T-068/98 (Alejandro Martinez Caballero, M. P.). https://www. corteconstitucional.gov.co/relatoria/1998/T-068-98.htm

Corte Constitucional. (2002). Sentencia C-127/02 (Alfredo Beltran Sierra, M. P.). https://www. corteconstitucional.gov.co/relatoria/2002/c-127-02.htm

Corte Constitucional. (2003). Sentencia C-037/03 (Alvaro Tafur Galvis. M. P.). https://www. corteconstitucional.gov.co/relatoria/2003/C-037-03.htm

Corte Constitucional. (2005). Sentencia C-983/05 (Humberto Antonio Sierra Porto, M. P.). https://www. corteconstitucional.gov.co/relatoria/2005/C-983-05.htm

Corte Constitucional. (2010). Sentencia C-149/10 (Jorge Iván Palacio Palacio, M. P.). https://www. corteconstitucional.gov.co/relatoria/2010/C-149-10.htm 
Corte Constitucional. (2013). Sentencia C-435/13 (Mauricio González Cuervo, M. P.). https://www. corteconstitucional.gov.co/RELATORIA/2013/C-435-13.htm

Corte Constitucional. (2013). Sentencia C-624/13 (Jorge Ignacio Pretelt Chaljub, M. P.). https://www. corteconstitucional.gov.co/relatoria/2013/C-624-13.htm

Corte Constitucional. (2013). Sentencia C-826/13 (Luis Ernesto Vargas Silva, M. P.). https://www. corteconstitucional.gov.co/relatoria/2013/C-826-13.htm

Corte Constitucional. (2017). Sentencia C-358/17. (Carlos Bernal Pulido, M. P.). https://www. corteconstitucional.gov.co/relatoria/2017/C-358-17.htm

Corte Constitucional. (2018). Sentencia C-018/18 (Alejandro Linares Cantillo, M. P.). https://www. corteconstitucional.gov.co/relatoria/2018/C-018-18.htm

Corte Constitucional. (2018). Sentencia SU-095/18 (Cristina Pardo Schlesinger, M. P.). https://www. corteconstitucional.gov.co/relatoria/2018/SU095-18.htm

Corte Constitucional. (2019). Sentencia C-189/19 (Alejandro Linares Cantillo, M. P.). https://www. corteconstitucional.gov.co/relatoria/2019/C-189-19.htm

Corte Interamericana de Derechos Humanos (CIDH). (2016, 20 de octubre). Sentencia caso Trabajadores de la Hacienda Brasil Verde vs. Brasil. http://www.corteidh.or.cr/docs/casos/articulos/seriec_318_esp.pdf

Corte Interamericana de Derechos Humanos. (2020, 9 de abril). Declaración: Covid - 19 y derechos humanos: los problemas y desafíos deben ser abordados con prespectiva de derechos humanos y respetando las obligaciones internacionales. http://www.corteidh.or.cr/tablas/alerta/comunicado/declaracion_1_20_ESP.pdf

Duque Cante, N. (2017). Importancia de la categorización territorial para la descentralización y las relaciones intergubernamentales en Colombia. Derecho del Estado, (38), 67-95.

El Tiempo. (2020, 2 de abril). Claudia López, la nota más alta en manejo de emergencia entre alcaldes. Obtenido de https://www.eltiempo.com/politica/gobierno/encuesta-califico-a-claudia-lopez-e-ivan-duquefrente-al-coronavirus-480158

Escola, H. J. (1989). El Interés público como fundamento del derecho administrativo. Depalma.

García de Enterría , E. y Fernández , T. (1993). Curso de Derecho Administrativo. Civitas.

Garrido Falla, F., Palomar Olmeda, A., y Losada Angel, H. (2006). Tratado de derecho administrativo (12 ed., Vol. II). Tecnos.

Haberle, P. (2007). El Estado constitucional. Astrea.

Henderson, H. (2004). Los tratados internacionales de derechos humanos en el orden interno: la importancia del principio pro homine. IIDH, 71-99.

Hernández Osorio, C. (2020, 28 de abril). Los médicos que le tiran línea a Claudia López en la cuarentena. La Silla Vacía. https://lasillavacia.com/los-medicos-le-tiran-linea-claudia-lopez-cuarentena-76318

Lopera Mesa, G. (2006). Principio de proporcionalidad y ley penal. Centro de Estudios Políticos y Constitucionales.

Lopera, G. y Arias, D. (2010). Principio de proporcionalidad y derechos fundamentales en la determinación de la pena. Consejo Superior de la Judicatura.

Merkl, A. (2004). Teoría general del derecho administrativo. Comares. 
Molano López, M. (2005). Transformación de la función administrativa. Pontificia Universidad Javeriana.

Molina Betancur, C. (2004). Jurisprudencia constitucional y territorio. Opinión Jurídica, 11-42.

Montalvo Abiol, J. C. (2010). Concepto de orden público en las democracias contemporáneas. RJUAM, (22), 197-222.

Montalvo Abiol, J. (2011). Interés general y administración contemporánea. Universitas, (14), 129-149. http://universitas.idhbc.es/n14/14-08.pdf

Navarro, P. (1993). Sistema jurídico, casos difíciles y conocimiento del derecho. Doxa, (14), 243-268.

Negishi, Y. (2017). The Pro Homine Principle's Role in Regulating the Relationship between Conventionality Control and Constitutionality Control. European Journal of International Law, 28(2), 457-481. https://doi.org/10.1093/ejil/chx030

Noticias Caracoltv. (2020, 6 de mayo). Duque sorprende con elogio a Claudia López, pese a que ella sigue con sus reparos al gobierno. https://noticias.caracoltv.com/coronavirus-covid-19/duque-sorprende-conelogio-claudia-lopez-pese-que-ella-sigue-con-sus-reparos-al-gobierno-nid228070-ie35596

Organización de Estados Americanos (1969, 22 de noviembre). Convención Americana sobre Derecho Humanos. Pacto de San José. https://www.hchr.org.co/documentoseinformes/documentos/html/ pactos/conv_americana_derechos_humanos.html

Organización de Naciones Unidas (1969, 23 de mayo). Convención de Viena. Sobre el derecho de los tratados. http://www.oas.org/36ag/espanol/doc_referencia/convencion_viena.pdf

Organización Internacional del Trabajo (1930, 20 de junio). Convenio sobre el trabajo forzoso. https://www. ilo.org/dyn/normlex/es/f?p=NORMLEXPUB: $12100: 0:: N O:: P 12100 \_I L O \_C O D E: C 029$

Organización Internacional del Trabajo (1998, 18 de junio). Declaración de la OIT relativa a los principios fundamentales en el trabajo y su seguimiento. https://www.ilo.org/declaration/thedeclaration/ textdeclaration/lang- es/index.htm

Ortiz, H. (2010, julio-diciembre). Ius Cogens Laboral y sus aportes al trabajo decente en un mundo global-glocal-regional. (U. R. Urdaneta, Ed.) Cuaestiones Jurídicas, IV(2), 85-107.

Parejo Alfonso, L. (2009). El concepto de derecho administrativo. Universidad Externado de Colombia.

Rekosh, E. (2005). Who Defines The Public Interest? Public Interest Law Strategies in Central and Eastern Europe. International Journal on Human Rigths, 2(2), 167-179. https://sur.conectas.org/wp-content/ uploads/2017/11/sur2-eng-rekosh.pdf

Rivero, J. (2002). Páginas de Derecho Administrativo. Temis y Universidad del Rosario.

Robledo Silva, P. (2006). Hacia la construcción de un concepto de autonomía territorial en la Constitución colombiana. Derecho del Estado, (18), 127-152.

Semana. (2020a, 1 de abril). OPS da razón a la alcaldesa Claudia López sobre tiempo de cuarentena. https:// www.semana.com/nacion/articulo/coronavirus-ops-da-razon-a-claudia-lopez-sobre-tiempo-decuarentena/660649

Semana. (2020b, 6 de abril). ¿Claudia López prolongará la cuarentena en Bogotá hasta junio? https:// www.semana.com/nacion/articulo/coronavirus-hasta-cuando-ira-la-cuarentena-en-bogota/661829

Semana. (2020c, 2 de mayo). Los colombinos, con estrés y miedo por el coronavirus. https://www.semana.com/ nacion/articulo/coronavirus-los-colombianos-viven-con-estres-y-miedo/667483 
Stone Sweet, A. y Matthews, J. (2013). Proporcionalidad y constitucionalismo. Un enfoque comparativo Global. Universidad Externado de colombia.

Vedel, G. (1980). Derecho Administrativo. Aguilar.

Vega Ruiz, M. y Martínez, D. (2002). Los principios y derechos fundamentales en el trabajo. OIT. 